\title{
Electric Vehicle Requirements for Operation in Smart Grids
}

\author{
Marra, Francesco; Sacchetti, Dario; Træholt, Chresten; Larsen, Esben
}

Published in:

Innovative Smart Grid Technologies (ISGT), 2011

Link to article, DOI:

10.1109/ISGTEurope.2011.6162648

Publication date:

2011

Document Version

Early version, also known as pre-print

Link back to DTU Orbit

Citation (APA):

Marra, F., Sacchetti, D., Træholt, C., \& Larsen, E. (2011). Electric Vehicle Requirements for Operation in Smart Grids. In Innovative Smart Grid Technologies (ISGT), 2011 IEEE.

https://doi.org/10.1109/ISGTEurope.2011.6162648

\section{General rights}

Copyright and moral rights for the publications made accessible in the public portal are retained by the authors and/or other copyright owners and it is a condition of accessing publications that users recognise and abide by the legal requirements associated with these rights.

- Users may download and print one copy of any publication from the public portal for the purpose of private study or research.

- You may not further distribute the material or use it for any profit-making activity or commercial gain

- You may freely distribute the URL identifying the publication in the public portal

If you believe that this document breaches copyright please contact us providing details, and we will remove access to the work immediately and investigate your claim. 


\title{
Electric Vehicle Requirements for Operation in Smart Grids
}

\author{
Francesco Marra, Student Member, IEEE, Dario Sacchetti, Chresten Træholt \\ and Esben Larsen
}

\begin{abstract}
Several European projects on smart grids are considering Electric Vehicles (EVs) as active element in future power systems. Both battery-powered vehicles and plug-in hybrid vehicles are expected to interact with the grid, sharing their energy storage capacity. Different coordination concepts for EVs are being investigated, in which vehicles can be intelligently charged or discharged feeding power back to the grid in vehicle-to-grid mode (V2G). To respond to such needs, EVs are required to share their battery internal data as well as respond to external control signals. In this paper, the requirements for the interaction of $\mathrm{EVs}$ with the electrical grid are presented. The defined requirements have been implemented on an EV test bed, realized by using real EV components. Charging/V2G tests on the EV test bed have shown that the presented requirements are sufficient to ensure an intelligent coordination of EVs into the electricity grid.
\end{abstract}

Index Terms - Electric vehicle, requirements, smart grids, virtual power plant

\section{INTRODUCTION}

$\mathrm{T}$ HE ongoing research on Smart Grids is playing a major role in the process of electrification of the transport sector.

In January 2008, the European Commission published the " $20-20$ by 2020 " package [1]. This includes targets for reducing the EU's greenhouse gas emissions by $20 \%$, with respect to 1990 levels, and increasing the share of final energy consumption from renewable sources to $20 \%$. Both of these targets have to be achieved by 2020 .

The electrification of transport, by means of plug-in EVs and plug-in Hybrid EVs (PHEVs) will most likely contribute in the coming years to achieve the $\mathrm{CO} 2$ target [2]. Battery-powered EVs are able to achieve zero-emissions during their driving cycles since all the energy needed is drawn out of the battery [3]. In the case of PHEVs, different classes of vehicles are available based on their system design. PHEVs combine both an electric system propelled by a battery and an internal combustion engine [4]. Also for these vehicles, the level of $\mathrm{CO} 2$ emission is much lower compared with the standard ICE cars. For simplicity, in this

The authors are grateful to the financial support from the Danish project "Electric vehicles in a Distributed and Integrated market using Sustainable energy and Open Networks", EDISON, which is funded by the ForskEl program (ForskEL Project Number 081216).

Mr. F. Marra, Mr. D. Sacchetti, Mr. C. Træholt and Mr. E. Larsen are within the Centre for Electric Technology, Department of Electrical Engineering, Technical University of Denmark, 2800 Kgs. Lyngby, Denmark (e-mail: fm@elektro.dtu.dk). paper we will refer to EVs, including both plug-in hybrid and battery-powered vehicles.

Even though the replacement of conventional cars by EVs could give the opportunity for lowering $\mathrm{CO} 2$ emission levels, it is expected that a large-scale penetration of these new vehicles will increase the electricity consumption due to the charging process. Therefore, the need to manage the charging of EVs, so to optimize their interaction with the electrical grid, arises. If coordinated, EVs can provide multiple benefices, e.g. they can support the integration of renewable energy sources, thanks to their energy storage capability and they can participate in the provision of several power system services, including ancillary services [5]. But the intelligent operation of EVs into the grid will be possible provided the combination of:

- Grid-interactive EV architecture

- Open access to internal vehicle data

Several assessments on EV coordination have been carried out, based on the concept of a Virtual Power Plant (VPP) for the aggregation of EV fleets. In the Danish Edison project [6], a VPP is dedicated to the intelligent charging/V2G operation of EVs. The interaction of such vehicles with the grid requires accessible system architecture on the EV side, which enables the EV coordinators to communicate with the vehicles and get the relevant internal vehicle data. The EV coordinator is able to elaborate the EV data collected and thereby send the control signals to the vehicles, in the form of charging/V2G schedules [7].

The requirements to achieve intelligent coordination of EVs within a VPP framework are presented in this paper. The EV system architecture is described in the work, with emphasis on the hardware and software interfaces involved.

The implementation of such requirements is then performed at laboratory level, on an EV test bed, using real EV components. Tests and measurements of a charging/V2G schedule have been conducted on the EV test bed, showing the effectiveness of the defined requirements.

\section{RELATED WORK}

In this section the conceptual framework developed in the Danish Edison project [5] is presented as a platform which conducts to the definition of EVs system requirements for intelligent coordination.

The reason for choosing the Edison VPP for the study is because this VPP has been specifically designed for EV coordination, rather than for others distributed energy 
resources (DERs).

In the Edison project, the interaction between the plug-in EVs and the electrical grid is considered using different hierarchical levels:

- Centralized EV coordination

- Local control at the EV interface

As depicted in Fig. 1, the control of EVs takes place at local level on the EV interface. The individual charging stations (CS) that receive the charging/V2G requests by the $\mathrm{EV}$ coordinator and send the control signals to the EVs.

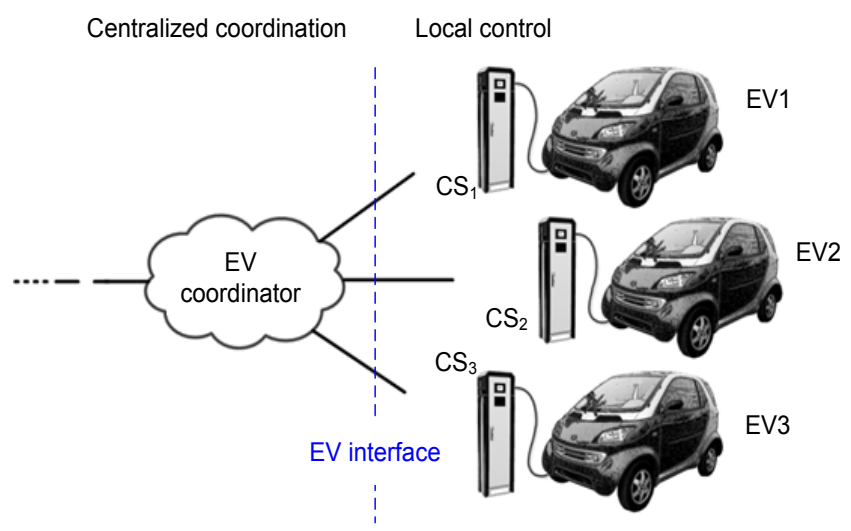

Fig. 1. EV coordination in the Edison project

The charging/discharging of vehicles is handled utilizing the necessary electrical circuitry and communication interfaces which lie on the EV interface. Such components could be partly included in the charging infrastructure, i.e. in the charging stations, as well as on board the vehicle.

At a higher hierarchical level, a centralized EV coordinator, the Edison VPP, aggregates and elaborates the actual status of the vehicles, thus it generates the schedule. As a result, the VPP sends the control signals to the plugged EVs so to coordinate their charging/V2G operation.

It is reminded that the Edison VPP operates in a multientities platform interfacing with other players, as depicted in the diagram of Fig. 2.

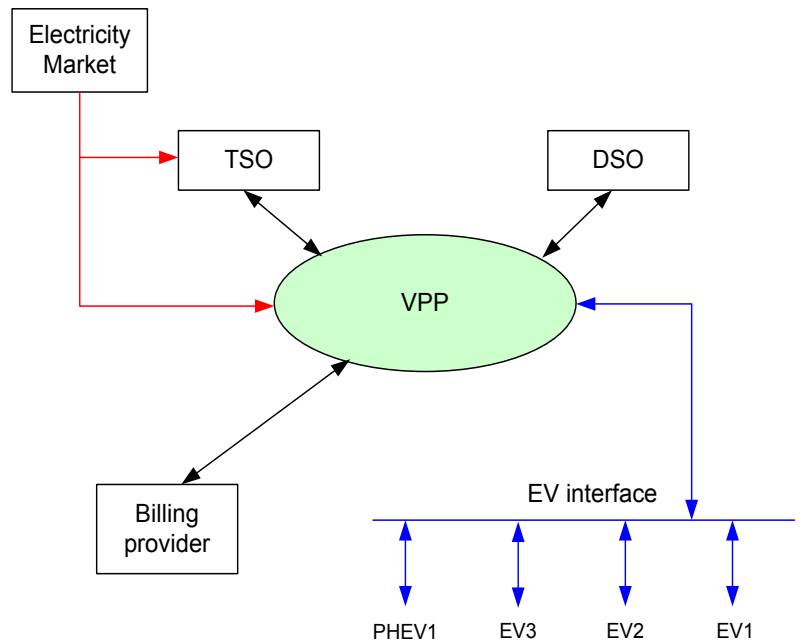

Fig. 2. Concept of EDISON Virtual Power Plant
In this context, each vehicle is encouraged to actively participate in supporting the power system where increasing amount of renewable energies is expected. Therefore the intelligent operation of EVs, within the illustrated framework, is expected to take place at the EV interface. The other interfaces in the framework are: a transaction interface with a Billing Provider to allow the billing of energy during charging or V2G operation; a Transmission System Operator (TSO) interface, where a Balance Responsible Party is involved to create and submit mandatory power schedules for the correct operation of the power system; an Electricity Market interface and a Distribution System Operator (DSO) interface to collect the grid status of every connected EV [5].

In this paper, the focus is dedicated to the requirements definition on the EV interface for the interaction between EVs and VPP.

\section{DEFINITION OF REQUIREMENTS}

The coordination of EV fleets can be achieved given that vehicles have an accessible hardware and software architecture which can be monitored and controlled during plug-in periods.

The requirements for achieving the monitoring and control functions of EVs in a charging/V2G framework should therefore include the following:

- monitoring of internal vehicle data

- control of charging/V2G operation

\section{A. Monitoring of internal vehicle data}

The need for EV coordination involves the monitoring of several internal vehicle data. This requirement entails the real-time communication with the Battery Management System (BMS) of the vehicle. Accessing the info contained in the vehicle BMS is fundamental to the VPP in order to define the energy status of the vehicle and other relevant parameters. The following internal vehicle data, Fig. 3, are required for the EV status identification:

- $\quad$ Nominal battery energy, $E_{n}$

- Battery State-of-Charge, $S O C$

- Instant power during charging/V2G, Power

The nominal energy of the battery is an invariant parameter which is expressed in $\mathrm{kWh}$ as follows:

$$
E_{n}=V_{B A T T} \cdot C_{n}
$$

where $C_{n}(\mathrm{Ah})$ is the nominal capacity of the battery pack [8], while $V_{B A T T}(\mathrm{~V})$ is the nominal voltage of the battery pack. The nominal energy is required by the VPP since it represents the absolute reference of energy of the vehicle.

The SOC of the vehicle battery, as defined in [9], is the measure of the charge left in the battery with respect to its nominal capacity. This can be expressed as follows:

$$
S O C=\frac{C}{C_{n}}
$$

where $C(\mathrm{Ah})$ is the actual capacity contained in the battery at the time of measuring. 
The third information needed to the VPP is the power used by the EV during charging/V2G operations. This could be achieved using either smart meters on a charging station or possibly BMS data.

In smart charging applications, the charging/discharging power should be measured in real-time and the information sent back to the VPP which keeps track of the energy exchanged between the EV and the grid. The power levels used are constrained by the charging infrastructure available, e.g. the size of the on-board EV chargers, the grid electrical cables, the transformer ratings etc. The EV coordination strategies are therefore aiming to avoid any grid reinforcement [10].

The fast-charging scenario of EVs is not considered in this paper, as it does not necessarily require any EV coordination. Fast-charging entails the installation of ad hoc charging infrastructures due to the high power demand as well as it requires an accurate charging management which cannot be influenced by higher level coordination [11].

Based on the existing electrical grid infrastructure, the most common power levels defined for EVs charging are listed in Table I.

TABLE I

CHARGING/DischaRGING POWER LEVELS

\begin{tabular}{cccc}
\hline AC current & AC voltage & Grid connection & Power \\
\hline $10 \mathrm{~A}$ & $230 \mathrm{~V}$ & single phase & $2.3 \mathrm{~kW}$ \\
$16 \mathrm{~A}$ & $230 \mathrm{~V}$ & single phase & $3.7 \mathrm{~kW}$ \\
$32 \mathrm{~A}$ & $230 \mathrm{~V}$ & single phase & $7.4 \mathrm{~kW}$ \\
$16 \mathrm{~A}$ & $400 \mathrm{~V}$ & three-phase & $11 \mathrm{~kW}$ \\
$32 \mathrm{~A}$ & $400 \mathrm{~V}$ & three-phase & $22 \mathrm{~kW}$ \\
\hline
\end{tabular}

The five listed charging options are referred to the AC side of the EV chargers. It is expected that all on-board chargers for EVs will fall in one of these use cases [12]. The same power levels could be used with vehicles entering the V2G mode, when provided with such a feature.

\section{B. Control of Charging/V2G operation}

Monitoring the internal vehicle data is not enough alone to achieve smart charging/discharging of EVs. In fact, the control requirement is also needed to achieve the following:

- Activation of the charging mode

- Activation of the V2G mode

- Control of power set point, $P_{-}$set

EVs are controllable, provided that the EV charging/V2G components can receive a control signal sent by the EV coordinator, namely the Edison VPP, and respond accordingly. Control is needed to satisfy the activation of the operation mode, primarily. Secondly, the control requirement can provide the regulation of the power level used both during charging and V2G operation.

The defined requirements of monitoring and control are summarized in Fig. 3. In Fig. 3 (a) the BMS data and the measured power are represented as monitoring requirements of an on-board charger type of EV.

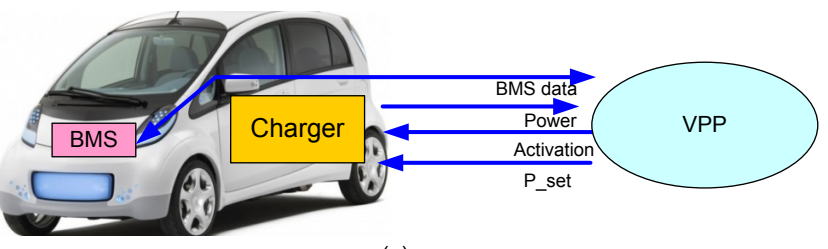

(a)

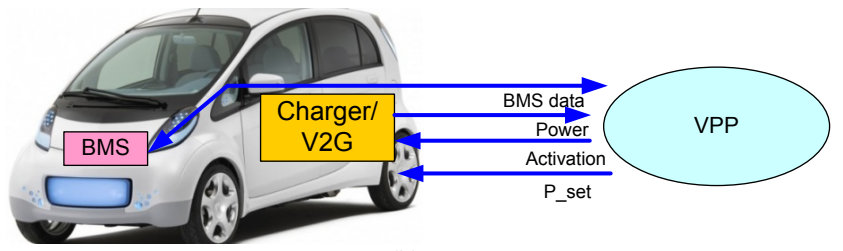

(b)

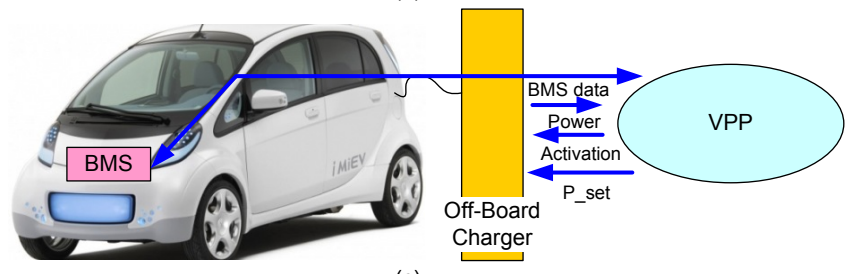

(c)

Fig. 3. Requirements for charging/V2G operation. (a) On-board charging concept. (b) On-board charging/V2G concept. (c) Off-board charging/V2G concept

The control requirements of the charging operation are depicted with an activation signal and $P_{\text {set }}$ set signal respectively. Both the control signals are sent by the VPP. Similarly, in Fig. 3 (b), an EV with bi-directional power components is represented. The required monitoring functions are the same as in the previous case. The only difference lies in the control requirements, where this time the activation and $\mathrm{P}$ _set control signals are used to control either the charging or the V2G operation. Finally, in Fig. 3 (c) the case of EV with off-board charger is represented. Some vehicles manufacturers, such as Nissan Leaf, have implemented the option of using an external charger [13], or DC charger, generally more powerful than the on-board one. The off-board charger is a future candidate for the last two power levels of Table I, corresponding to $11 \mathrm{~kW}$ and $22 \mathrm{~kW}$ respectively [14]. The defined requirements are also valid under the off-board charging case: each $\mathrm{EV}$ is required to send the BMS data and the charging/V2G power information to the VPP. The control requirement is still realized by the activation signal and the $P$ set signal sent by the VPP to the vehicle. Due to grid constraints, the $P_{-}$set signal could have a significant role in the off-board charging concept [15].

\section{IMPLEMENTATION OF REQUIREMENTS}

The defined requirements have been summarized in the diagram of Fig. 4, according to the definition performed in the previous section.

Monitoring and control requirements have been implemented on a real EV test bed, Fig. 5, considering the case of an EV capable of both charging and V2G, as depicted in Fig. 3 (b). 


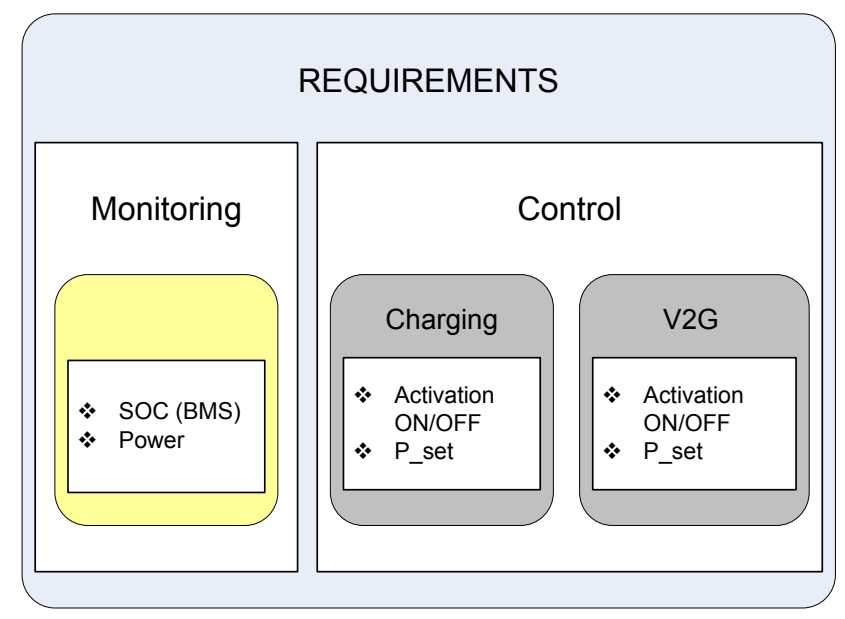

Fig. 4. Requirements for EV operation is Smart Grids

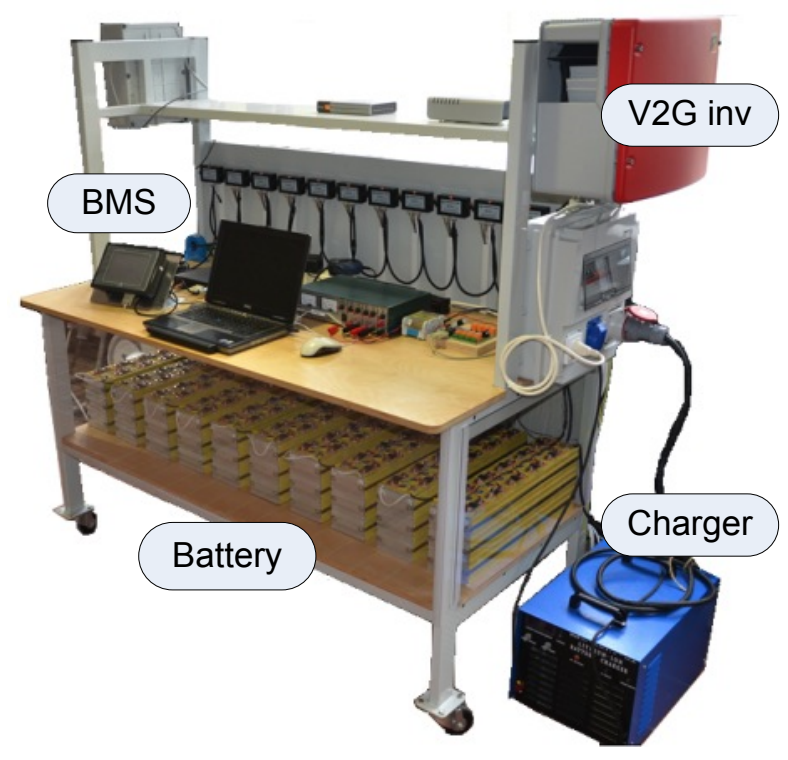

Fig. 5. EV test bed

\section{A. EV test bed}

The EV test bed is an experimental setup composed of real EV components; it is capable of charging and V2G operation and designed prioritizing open access to communication and control.

The EV test bed is composed by the following components:

- $\quad$ Battery pack: $\mathrm{V}_{\text {BATT }}=363 \mathrm{~V}, \mathrm{C}_{\mathrm{n}}=40 \mathrm{Ah}$, $\mathrm{E}_{\mathrm{n}}=14.5 \mathrm{kWh}$

- Charger: $0-5.5 \mathrm{~kW}$

- V2G inverter: 0 - $4 \mathrm{~kW}$

- BMS: battery pack voltage, total current, instant power, temperature, SOC, actual capacity C, nominal energy $E_{n}$, nominal capacity $C_{n}$

- On-board computer for communication between $\mathrm{EV}$ and VPP

The hardware architecture is composed by two separate components for charging and $\mathrm{V} 2 \mathrm{G}$ operation, since the choice for a bidirectional operation came at a later stage in the design.
The battery pack was sized with nominal voltage of $363 \mathrm{~V}$, considering the requirement for $\mathrm{V} 2 \mathrm{G}$ operation and the common EVs design concepts. The battery is composed of 110 single cells, connected in series, lithium-iron-phosphate (LFP) technology based. A BMS is attached to the battery pack, Fig. 6, and is composed of 11 voltage acquisition modules each of whom acquires the voltage of 10 battery cells. A current acquisition module is used to acquire the current flowing in or out of the battery pack. Using the voltage and current information, the BMS is able to estimate the SOC of the battery pack. The nominal battery capacity and the nominal energy of the battery pack are invariant values that are stored in the BMS data memory and depend exclusively on the battery design.

The battery charger has a charging power of 0 to $5.5 \mathrm{~kW}$, efficiency of about 0.88 and power factor (PF) of 0.9 at rated power. The $\mathrm{V} 2 \mathrm{G}$ inverter has a power range of 0 to 4 $\mathrm{kW}$, efficiency of about 0.95 and PF of 1 . An onboard computer is used to interface with all hardware components described.

\section{B. Implementation of Monitoring}

As indicated in Fig. 4, the SOC and the real time Power are the two essential requirements for monitoring the EV status. To implement the monitoring requirements, a software interface which reads data from the BMS has been implemented, using a serial communication protocol. The diagram of Fig. 6 describes the architecture for reading the different BMS data on the EV test bed.

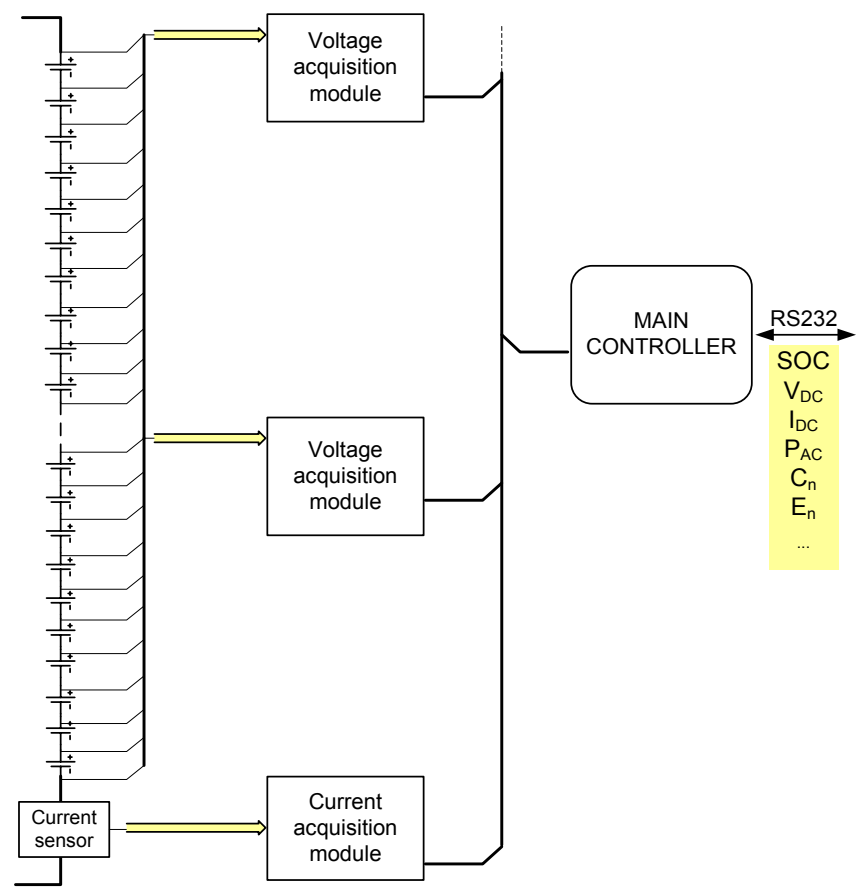

Fig. 6. Implementation of monitoring using the BMS on the EV test bed

Data acquired by the voltage and current acquisition modules is collected in the BMS controller, namely Main Controller, which computes the SOC level of the EV battery. The SOC, as well as the other real time data, are extracted using serial commands, over a serial port RS232 which is installed on the main controller. 


\section{Implementation of Control}

Following the diagram of Fig. 4, the requirements for control can be split between the charging and the V2G operation. During charging or V2G operation, the EV test bed is required to respond to both the activation request and the $\mathrm{P}_{-}$set request sent by the VPP. Therefore the requirements for control are the same for both operation modes.

The activation requirement is implemented directly on the DC side of the power components, by using two DC contactors for the charger and the $\mathrm{V} 2 \mathrm{G}$ inverter respectively. The diagram of Fig. 7 depicts the system architecture which realizes the control requirements. The onboard EV computer receives the charging/V2G schedule by the VPP, in the form of TCP/IP data packets, thus it converts the schedule into control signals for the contactors, through an I/O interface. The contactors are rated at $900 \mathrm{~V}, 200 \mathrm{~A}$, and are connected on the positive terminal of the battery. The contactors are normally open, thus a voltage of $24 \mathrm{~V}$ is applied on the contactor's coil by the I/O interface when an activation request is sent by the VPP.

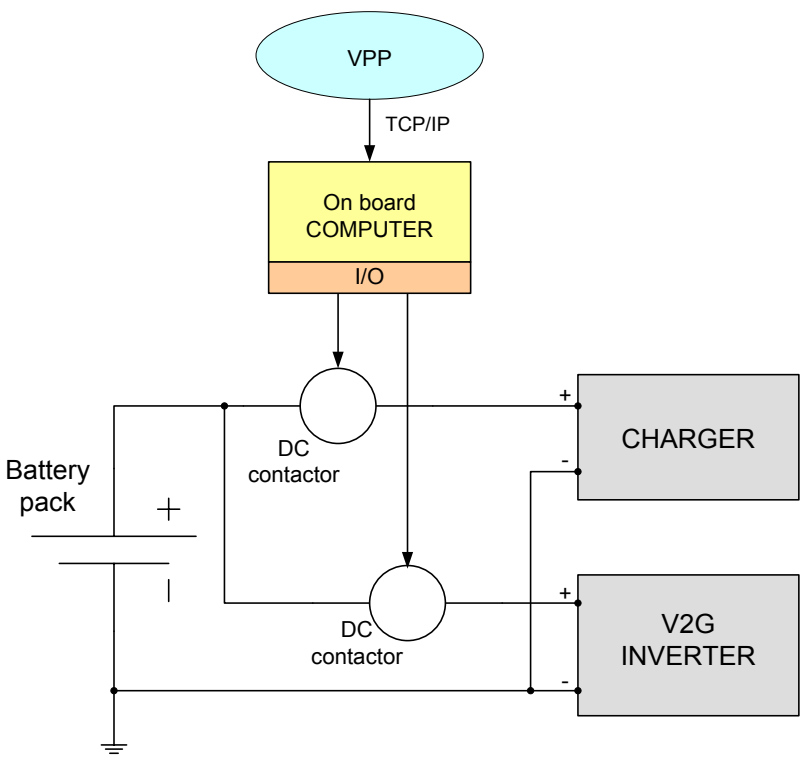

Fig. 7. Implementation of activation requirement

The power set point requirement, $\mathrm{P}_{-}$set, has been implemented for the $\mathrm{V} 2 \mathrm{G}$ operation. A software interface using the communication standard RS485 was designed to communicate to the inverter the set point of the power level.

\section{Coordination of Monitoring and Control}

The implemented requirements of monitoring and control are not stand-alone functions taking place at different moments. A software interface, including both requirements, has been implemented to interface the monitoring and control functions with the VPP. The interface works as software plug-in which communicates with the BMS, the charger and the V2G inverter; it sends the collected data to the VPP for elaboration and it gets back the VPP requests for charging/V2G operation.

On top of the software plug-in, a server based on the communication Standard IEC 61850 was used to interface with the VPP [16].

\section{TESTS AND RESUlts}

The implemented requirements of monitoring and control have been tested on the EV test bed, using a charging/V2G schedule generated by the Edison VPP. The power level of $2.3 \mathrm{~kW}$ for charging and $\mathrm{V} 2 \mathrm{G}$, corresponding to the home charging case of Table 1, has been used. The schedule used in the tests is described by the following sequence of operations:

- Activation of charging operation, at 15:28:56; Charging power level set at $2.3 \mathrm{~kW}$

- Deactivation of charging operation, at 15:43:56

- Activation of V2G operation, at 15:43:59; V2G power level set at $2.3 \mathrm{~kW}$

- Deactivation of V2G operation, at 15:58:56

- Activation of charging operation, at 15:58:59; Charging power level set at $2.3 \mathrm{~kW}$

The activation and deactivation apply to both charging and V2G operation. The control requirement has been tested setting a power level of $2.3 \mathrm{~kW}$ for the $\mathrm{V} 2 \mathrm{G}$ operation. The charging power is instead fixed to $2.3 \mathrm{~kW}$. To guarantee a safe change of operation from charging to $\mathrm{V} 2 \mathrm{G}$ and vise versa, a time delay of 3 seconds is introduced via software between two consecutive commutations.

To verify that the defined requirements are met, the instant power and the SOC have been measured. All measurements were performed with a sample time of 1 second. The power on the grid side $\left(\mathrm{P}_{\mathrm{AC}}\right)$ was measured on the grid connection point of the EV test bed. In addition to the essential monitoring requirements of SOC and Power, the current $\mathrm{I}_{\mathrm{DC}}$ flowing into the battery and the terminal voltage of the battery pack $\mathrm{V}_{\mathrm{DC}}$, were measured during the test. The power on the battery side has been then calculated off-line and compared with $\mathrm{P}_{\mathrm{AC}}$. This allows estimating the efficiency during charging and $\mathrm{V} 2 \mathrm{G}$ operation.

Test results are shown in Fig. 8 (a) and (b). In Fig. 8 (a) the power profile measured on the grid side, $\mathrm{P}_{\mathrm{AC}}$, and the SOC profile are depicted. The initial condition of the SOC is $66 \%$ and the SOC resolution is $1 \%$. It is observable that the charging profile, with duration 15 minutes, brings the SOC to a level of $70 \%$. The activation of the $\mathrm{V} 2 \mathrm{G}$ operation takes longer than the charging activation; this is due to the synchronization time with the grid frequency and check of the grid voltage, which occurs in the V2G inverter. This issue will be further addressed in a future work. A steady power profile, $\mathrm{P}_{\mathrm{AC}}$, of $2.3 \mathrm{~kW}$ is observable during both charging and discharging. This enlighten that both the charger and the $\mathrm{V} 2 \mathrm{G}$ inverter correctly response to the power set point of $2.3 \mathrm{~kW}$. A negative sign convention is used for representing the power during V2G operation. 

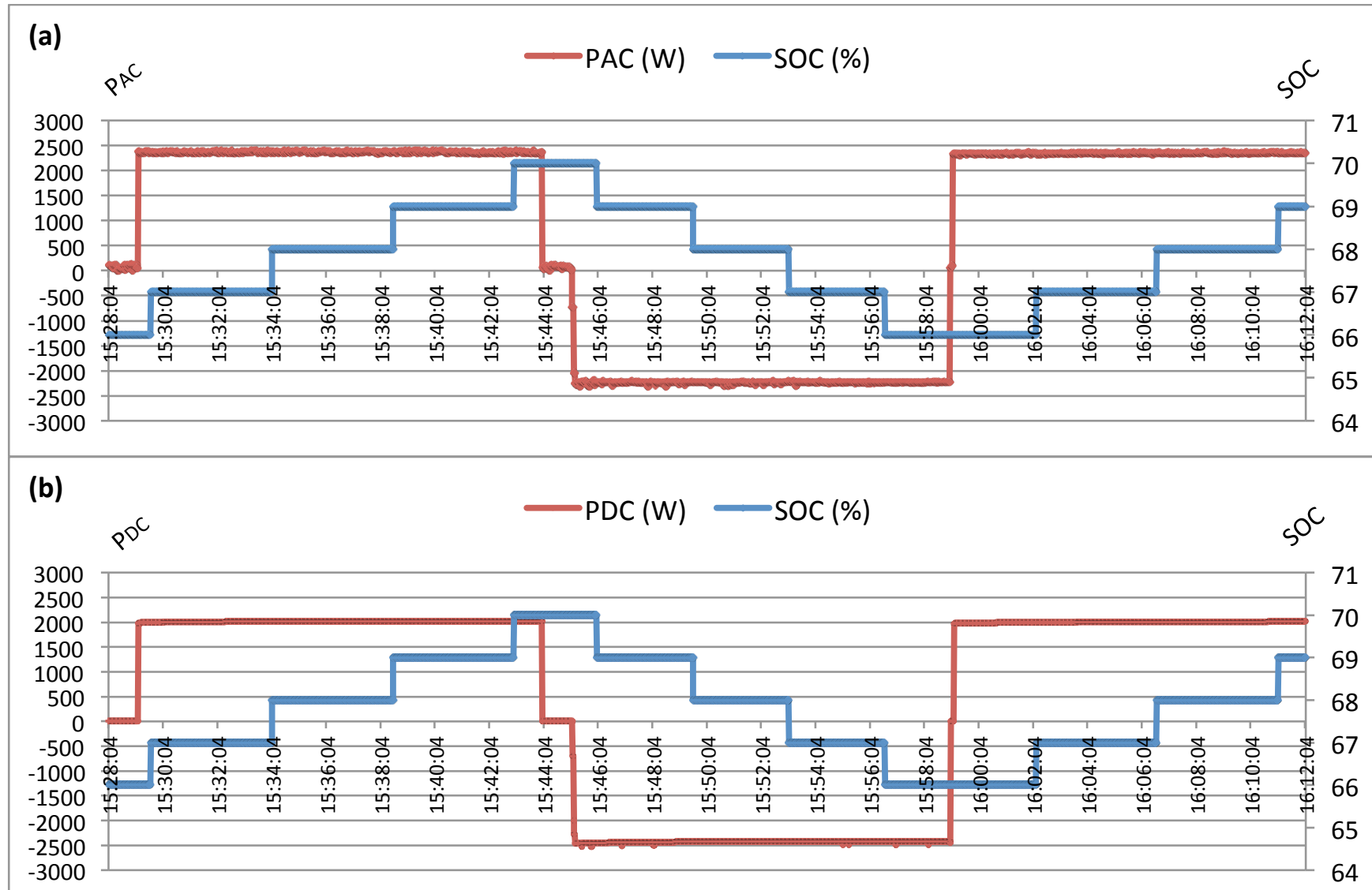

Fig. 8. Tests of monitoring and control requirements during charging and V2G operation. (a) Measurement of $\mathrm{P}_{\mathrm{AC}}$ and SOC. (b) Calculated $\mathrm{P}_{\mathrm{DC}}$ based on measurements of $I_{D C}$ and $V_{D C}$ on the battery side and measurement of SOC

In Fig. 8 (b) the calculated power $\mathrm{P}_{\mathrm{DC}}$ is shown based on the measurements of $I_{D C}$ and $V_{D C}$. In (3) the formula used to calculate $\mathrm{P}_{\mathrm{DC}}$ is shown:

$$
P_{D C}=V_{D C} \cdot I_{D C}
$$

where the current $I_{D C}$ during charging is taken with a positive sign, while with a negative sign during $\mathrm{V} 2 \mathrm{G}$ operation.

In (4) and (5) the power $P_{D C}$ is expressed in function of the efficiency $\eta$ of the charger and the $\mathrm{V} 2 \mathrm{G}$ inverter respectively.

$$
\begin{aligned}
& P_{D C}=\eta_{C H} \cdot P_{A C} \\
& P_{D C}=\eta_{V 2 G} \cdot P_{A C}
\end{aligned}
$$

This efficiency is well estimated based on the calculated $\mathrm{P}_{\mathrm{DC}}$ shown in Fig. 8 (b) and the measured $\mathrm{P}_{\mathrm{AC}}$. In particular, during charging, it is estimated an efficiency of about $87 \%$, from grid to battery, while during $\mathrm{V} 2 \mathrm{G}$ operation it is observed an efficiency of about $95 \%$ from battery to grid. This confirms the features claimed by the manufacturer.

Further analysis on the charging/V2G efficiency is not treated in this paper, since the scope is to define the requirements for $\mathrm{EV}$ operation in smart grids.

\section{CONCLUSIONS}

The requirements needed for electric vehicles interaction in a smart grid scenario have been addressed in this work. The requirements have been defined with respect to the charging and V2G operation mode which an EV could enter during plug-in periods. The study identified that the SOC of the battery and the power exchanged between EVs and the grid are essential monitoring requirements. The activation/deactivation and the power set point have been identified as fundamental control requirements for the EVs charging/V2G operation. The defined requirements have been implemented on a real EV test bed and validation of intelligent EV operations within a VPP framework has been presented. The performed tests, based on the charging/V2G schedule generated by the Edison VPP, have shown that the defined requirements are sufficient to achieve an intelligent coordination of EVs. Experimental tests have shown that 1 second resolution for monitoring and control is possible and that this is enough to ensure an intelligent operation of EVs. The intelligent management of the charging/V2G operation is possible given an open access to BMS data, for monitoring, and to a vehicle computer for control. Estimating power losses and efficiency of the charging/discharging cycles is also possible given the defined requirements. In all, the findings offer to future EV coordinators and grid operators the possibility to increase their interaction for an intelligent deployment of EVs. Also, the results could serve as a stimulus for EV manufacturers to 
consider EVs as a more flexible resource, on which the monitoring and control can be externally managed.

\section{REFERENCES}

[1] European Commission, "20 20 by 2020 Europe's climate change opportunity", COM (2008) 30 final, Brussels, 2008.

[2] Energinet.dk, "Environmental report 2010", online, 2010

[3] P. Morrison, A. Binder, B. Funieru, C. Sabirin, "Drive train design for medium-sized zero emission electric vehicles", 13th European Conference on Power Electronics and Applications, 2009.

[4] K. Chen, A. Bouscayrol, A. Berthon, P. Delarue, D. Hissel, and R. Trigui, "Global modeling of different vehicles", IEEE Vehicular Technology Magazine, 2009

[5] W. Kempton and J. Tomic, "Vehicle-to-grid power fundamentals: Calculating capacity and net revenue", J. Power Sources, vol. 144, no 1, pp. 268-279, Jun. 2005.

[6] C. Binding, D. Gantenbein, B. Jansen, O. Sundstrom, P. B. Andersen, F. Marra, B. Poulsen and C. Træholt, "Electric Vehicle Fleet Integration in the Danish EDISON Project - A Virtual Power Plant on the Island of Bornholm", IEEE Power \& Energy Society General Meeting, 2009.

[7] B. Jansen, C. Binding, O. Sundström, D. Gantenbein, "Architecture and Communication of an Electric Vehicle Virtual Power Plant", in IEEE Proc. First IEEE International Conference on Smart Grid Communications, 2010

[8] Thunder Sky, LFP Li-ion battery user manual, 2009

[9] J. D. Dogger, B. Roossien, and F. Nieuwenhout, "Characterization of Li-Ion Batteries for Intelligent Management of Distributed GridConnected Storage", IEEE Trans. on Energy Conversion, Vol. 26, No. 1,2011

[10] K. Clement-Nyns, E. Haesen and J. Driesen, "The Impact of Charging Plug-In Hybrid Electric Vehicles on a Residential Distribution Grid", IEEE Transactions on Power Systems, Vol. 25, No. 1, 2010.

[11] B. G. Kim, F. P. Tredeau and Z. M. Salameh, "Fast Chargeability Lithium Polymer Batteries", in IEEE Power and Energy Society Conf., 2008.

[12] F. Marra, C. Træholt, E. Larsen, Q. Wu, "Average Behavior of Battery-Electric Vehicles for Distributed Energy Studies", in IEEE Proc. Innovative Smart Grid Technology Europe, 2010

[13] Nissan Leaf Electric Car, Charging info, www.nissanusa.com.

[14] Siemens AG, "Charge CP700A - The charging point with built in safety", online, 2011

[15] J. A. Pecas Lopes, F. J. Soares, P. M. Rocha Almeida, "Integration of Electric Vehicles in the Electric Power System", in IEEE Proc., Vol. 99, No. 1, 2011

[16] A. Bro Pedersen, E. Bragi Hauksson, P. Bach Andersen, B. Poulsen, C. Træholt, and D. Gantenbein "Facilitating a generic communication interface to distributed energy resources", in IEEE Proc. First IEEE International Conference on Smart Grid Communications, 2010 